\section{The pursuit of excellence}

Paul Hébert's call for the pursuit of excellence in health care, health education and health research in the interests of innovations for better health outcomes $^{1}$ is timely and welcome. Innovation in health will only come about by an explicit determination to integrate the scientific foundations of innovation; discovery, clinical, services, health behavior and promotion, and implementation. Hébert correctly identifies systems challenges as particular barriers to the pursuit of these laudable goals. Moreover, the evidence base for the necessary integrative approaches is penurious. ${ }^{2}$ This begs the following observation: While health professional pursuits in care, education, and research are necessary, they are not sufficient. Required is a focus on systems strengthening through an engagement with policy professionals within Canada's health and social services jurisdictions.

\section{R.J. Riopelle MD}

Chair, Department of Neurology and

Neurosurgery McGill University, Montréal, Que.

\section{REFERENCES}

1. Hébert PC. Why the pursuit of excellence matters [editorial]. CMAJ 2010;182:121.

2. Mitton C, Adair CE, Mckenzie E., et al. Knowledge transfer and exchange: review and synthesis of the literature; The Milbank Quarterly 2007; 85: 729-68.

For the full letter, go to: www.cmaj.ca/cgi/eletters /182/2/121\#275616

DOI:10.1503/cmaj.110-2036

\section{Tough choices?}

In "Tough choices: private sale of drugs in public hospitals," the authors base their argumentation on a sleightof-pen by using the concept of "medical necessity" or lack thereof. The absurdity of the medical necessity argument is readily apparent from the discrepancy in the access to cancer drugs across Canadian provinces. Could anyone argue rationally that alemtuzumab is "medically necessary" in British
Columbia or Manitoba but not in Ontario or Quebec? Can the state deny a patient a beneficial service, if the residual cost-utility falls below the customary threshold because a patient bears its major cost? The answer to this conundrum lies not in the blunt instrument of new legislation spawned by ideology, but in carefully individualized decision processes that involve all the major stakeholders.

\section{Ralph F. Bloch MD PhD MSc}

Professor, clinical epidemiology and biostatistics, Faculty of Health Sciences, McMaster University, Hamilton, Ont.

\section{REFERENCE}

1. Flood CM, Hardcastle L. Tough choices: private sale of drugs in public hospitals. CMAJ 2010;182:374-6

For the full letter, go to: www.cmaj.ca/cgi/eletters /182/4/374\#298095

DOI:10.1503/cmaj.110-2044

\section{Indigenous health}

In the Feb. 23, 2010, issue of CMAJ, the health of indigenous people regarding food insecurity, epidemiology of diabetes ${ }^{2}$ and birth outcomes ${ }^{3}$ was summarized. Traditional indigenous foods were not studied in the food security study. These foods, which include fish, would provide some vitamin D and significant levels of omega 3 fatty acids. However, environmental contaminants in these foods are rising and mercury is certainly a concern. There is emerging evidence that inadequate maternal vitamin D levels may increase the risk of developing diabetes in the offspring, pre-eclampsia in pregnancy, primary cesarean section rates and increased bacterial vaginosis in the first trimester. Low omega 3 fatty acid intake may contribute to the development of preeclampsia, preterm births and other adverse pregnancy outcomes.

In 2007, the Canadian Pediatric Society recommended increased vitamin D levels, especially in the Inuit and First Nations who live at higher latitudes. Improving vitamin D status is a very inexpensive intervention costing pennies a day. Omega 3 fatty acid intake recommendations in pregnancy have been around since 1999. Providing purified omega 3 supplements, although more expensive, would avoid the mercury and other toxicants found in contaminated traditional foods. Studies applying these recommendations and following outcomes may show considerable improvement in the health of the indigenous population and the rest of the nation as a whole.

Gerry K. Schwalfenberg MD

Assistant clinical professor, University of Alberta, Edmonton, Alta.

\section{REFERENCES}

1. Egeland GM, Pacey A, Cao Z, et al. Food insecurity among Inuit preschoolers: Nunavut Inuit Child Health Survey, 2007-2008. CMAJ 2010;182:243-8.

2. Dyck R, Osgood N, Lin TH, et al. Epidemiology of diabetes mellitus among First-Nations and nonFirst Nations adults. CMAJ 2010;182:249-56.

3. Luo Z.-C, Senécal S, Simonet F, et al. Birth outcomes in the Inuit-inhabited areas of Canada. CMAJ 2010;182:235-42.

For the full letter, go to: www.cmaj.ca/cgi/eletters /182/3/243\#297970

DOI:10.1503/cmaj.110-2042

\section{Children with brain injuries}

We read with interest the study "CATCH: a clinical decision rule for the use of computed tomography in children with minor head injury." The authors are to be congratulated for their efforts to clarify the role and potential benefits of computed tomography in children with minor head injuries. In addition to imaging studies, clinicians and researchers have used EEG to evaluate changes in the electrical activity of the brain following mild traumatic brain injury. In a retrospective analysis from January 2006 to December 2007 to assess the role of standard EEG recordings in children with mild traumatic brain injury, we concluded that the routine performance of an EEG is not indicated because in most of the cases it is unrevealing, and may lead to unnecessary diagnostic procedures. Notwith- 